\title{
Propuesta para la introducción de temas de historia, arte y literatura en la asignatura urología
}

\author{
Tundidor Bermúdez AM.
}

Hospital Guillermo Domínguez. Cuba.

Actas Urol Esp. 2008;32(9):868-872

\section{RESUMEN}

PROPUESTA PARA LA INTRODUCCIÓN DE TEMAS DE HISTORIA, ARTE Y LITERATURA

EN LA ASIGNATURA UROLOGÍA

Objetivo: Contribuir a la educación humanística de los estudiantes de Medicina.

Material y Métodos: Se realizó una investigación bibliográfica sobre temas de historia, arte y literatura relacionados con la Urología.

Resultados: Se propone la introducción de temas culturales en la asignatura Urología como motivación y complemento de los temas biomédicos, lo que se ilustra mediante ejemplos.

Conclusiones: La asignatura Urología puede contribuir a la educación humanística de los estudiantes de Medicina.

Palabras clave: Educación. Humanidades. Historia. Arte. Literatura. Medicina. Urología.

\section{ABSTRACT \\ PROPOSALS FOR THE INTRODUCTION OF HISTORY, ART AND LITERATURE ISSUES ON THE UROLOGY SUBJECT}

Objective: To contribute to the humanistic education of medical students.

Material and Methods: A bibliographic review was done on history, art and literature items in relation with Urology.

Results: The introduction of cultural items in the Urology subject, as a motivation and complement of the biomedical items, is proposed and illustrated by examples.

Conclusions: The Urology subject can contribute to the humanistic education of medical students.

Keywords: Education. Humanities. History. Art. Literature. Medicine. Urology.

$\mathrm{C}$ ada día es más evidente la importancia de la formación humanística de los estudiantes de Medicina. El avance en este terreno ha sido notable $y$, de una forma u otra, se han impartido cursos de humanidades en las tres últimas décadas en universidades de todo el mundo, tanto a estudiantes de pre como de postgrado ${ }^{1-3}$. Especial atención se ha prestado a los cursos de Extensión Universitaria (tanto intra como extracurriculares) que abordan el vínculo entre Literatura y Medicina ${ }^{3,4}$. Empero, esta educación humanística no tiene por qué verse limitada a las asignaturas especialmente concebidas con ese fin; las asignaturas biomédicas pueden asimismo contribuir a ella.
Todo intento de introducción de temas culturales en las asignaturas biomédicas debe cumplir -sin menosprecio de los restantes- los siguientes principios didácticos:

Principio de la sistematicidad: Consiste en la aplicación de las relaciones intermaterias y en la concepción de la concatenación universal de los fenómenos $^{5}$.

Principio de la asequibilidad: Exige que la enseñanza sea comprensible y posible, de acuerdo con las características individuales de los estudiantes ${ }^{5}$.

Principio de la solidez de los conocimientos: Es la lucha sistemática y enérgica contra el olvido, como un proceso psíquico normal. Se recuerda mejor 
aquello que se ha aprendido con mayor interés lógico, o lo que más gusta, o aquello sobre lo que más se ha insistido ${ }^{5}$.

El mejor modo de introducir los temas culturales ha de ser, pues, como motivación y complemento de los temas biomédicos.

El presente artículo tiene como objetivo proponer la introducción de temas culturales en la asignatura Urología, y mostrar ejemplos de cómo lograrlo.

\section{PROPUESTA METODOLÓGICA}

Introducir los temas culturales como motivación y complemento de los temas biomédicos correspondientes a la asignatura, como a continuación se ejemplifica:

Tema biomédico: Tratamiento de la fimosis.

Tema cultural: La circuncisión de los Semitas ${ }^{6-9}$.

La circuncisión tiene, al parecer, su origen en el Antiguo Egipto (2300 años antes de Cristo) y era utilizada originalmente para identificar a los esclavos. Adquiere un carácter religioso entre los pueblos semitas, actuales árabes y hebreos, considerados descendientes del patriarca bíblico Abraham. El libro del Génesis (17:9-14) relata: "Dijo de nuevo Dios a Abraham: (...) Este es mi pacto, que guardaréis entre mí y vosotros y tu descendencia después de ti: Será circuncidado todo varón de entre vosotros. Circuncidaréis, pues, la carne de vuestro prepucio, y será por señal del pacto entre mí y vosotros. Y de edad de ocho días será circuncidado todo varón entre vosotros por vuestras generaciones; el nacido en casa, y el comprado por dinero a cualquier extranjero, que no fuere de tu linaje. (...) Y el varón incircunciso, el que no hubiere circuncidado la carne de su prepucio, aquella persona será cortada de su pueblo; ha violado mi pacto."

En su novela "Entre todos los hombres", Frei Betto nos describe el modus operandi al recrear la circuncisión de Jesús de Nazaret: “... se presentan ante Matthia Ben Shemuel, sacerdote promovido (...) a la condición de mohel, circuncidador ritual de los nuevos israelitas. (...) Matthia Ben Shemuel empuña la fina hoja de un cuchillo de sílex, la pasa sobre la llama de una vela, dice la bendición, retira el culero, asegura el pene, lo estira y, con un corte preciso, arranca el prepucio. (...) El sacerdote descubre la cabeza del pene circuncidado y se asegura de que en lo que queda del prepucio no hay indicios de adherencia. Se inclina y lame el hilo de sangre dejado por la circuncisión. Acto seguido le cubre el miembro con una yerba medicinal y deja el glande descubierto."

Este rito ha sido también motivo de inspiración para las artes plásticas. En el Museo Nacional de Bellas Artes, de La Habana, puede apreciarse el óleo "La circuncisión de Cristo", del pintor holandés del siglo XVII Benjamín Gerritz Cuyp.

Tema biomédico: Uretritis aguda gonocócica.

Tema cultural: Las tribulaciones de Pedro Vicario ${ }^{10}$.

La novela "Crónica de una muerte anunciada" de Gabriel García Márquez, contiene una vívida descripción de un paciente con uretritis gonocócica: "Pedro Vicario cumplió el servicio durante once meses en patrullas de orden público. (...) Regresó con una blenorragia de sargento que resistió a los métodos más brutales de la medicina militar, y a las inyecciones de arsénico y las purgaciones de permanganato (...) agonizaba gota a gota tratando de orinar bajo los tamarindos (...) Era como orinar vidrio molido. (...) Estaba sudando frío del dolor (...)"

Tema biomédico: Litiasis vesical.

Tema cultural: La piedra en el camino de Hipócrates $^{11}$.

Una de las primeras contribuciones al estudio de la litiasis vesical se debe a Hipócrates, quien describió la enfermedad y sus síntomas. Sin embargo, se abstuvo de tratarla. En su época, las litotomías eran seguidas generalmente de fístulas urinarias incurables; era el precio de no morir en retención de orina, o de suprimir los terribles dolores que la piedra ocasionaba. Hipócrates lo declara con firmeza en su Juramento: "Nunca intentaré sacar la piedra de la vejiga, dejando este cuidado en manos de los prácticos." Con esta sentencia, Hipócrates, sin saberlo, aboga por la necesidad de la especialización dentro de la Medicina, y en contra del intrusismo profesional.

Tema biomédico: Complicaciones del cateterismo uretro-vesical.

Tema cultural: El nudo gordiano ${ }^{6,12}$.

Supongamos que entre nuestros pacientes tenemos un enfermo portador de sonda Foley. Vamos a proceder al cambio de la sonda en su propia casa, y al ir a retirar la que está puesta nos percatamos de que no podemos extraer el líquido que mantiene insuflado el globo o balón. Esta complicación se debe generalmente a obstrucción de la rama que comunica con el mismo. ¿Qué hacer? La solución tenemos que buscarla en la Historia, o acaso en la leyenda. 
Cuéntase que el carro que perteneció al rey Gordio (o Gordias), de Frigia, en el Asia Menor, fue consagrado a Zeus por su hijo el rey Midas. El nudo que unía al yugo con la lanza estaba formado tan artísticamente que no podían descubrirse los dos extremos. Sin embargo, prometía un antiguo oráculo el imperio de Asia a quien consiguiera desatarlo. Muchos fueron los que lo intentaron, infructuosamente. De ahí la expresión "nudo gordiano" para referirse a un problema de aparente difícil solución. Fue Alejandro de Macedonia, el renombrado "Alejandro Magno", quien con su espada cortó el nudo, solucionando así el problema.

$\mathrm{Y}$ es eso precisamente lo que debemos hacer: cortar la sonda a unos $5 \mathrm{~cm}$ del meato uretral. Si la obstrucción es distal al nivel de sección, el líquido fluirá libremente y el balón se desinflará. En caso contrario, será necesario remitir al paciente a un servicio urológico.

Tema biomédico: Cuadro clínico de la hiperplasia prostática.

Tema cultural: El manantial que envejeció ${ }^{13}$.

Gabriel García Márquez era ya un hombre maduro cuando escribió su novela "El amor en los tiempos del cólera". Esto quizás le permitiera describir con tanta exactitud los sintomas de un paciente con hiperplasia prostática: "Él fue el primer hombre al que Fermina Daza oyó orinar (...) y el ruido de su manantial de caballo le pareció tan potente e investido de tanta autoridad (...) Aquel recuerdo volvía con frecuencia a su memoria, a medida que los años iban debilitando el manantial, porque nunca pudo resignarse a que él dejara mojado el borde de la taza cada vez que la usaba. Él trataba de convencerla (...) de que aquel accidente no se repetía a diario por descuido suyo (...) sino por una razón orgánica: su manantial de joven (...) con los usos de la edad no sólo fue decayendo, sino que se hizo oblicuo, se ramificaba, y se volvió por fin una fuente de fantasía imposible de dirigir, a pesar de los muchos esfuerzos que él hacía por enderezarlo."

Tema biomédico: La castración en el tratamiento del adenocarcinoma prostático.

Tema cultural: La importancia de ser eunuco ${ }^{6,14}$.

La castración, como intervención quirúrgica en el humano, tiene su primera indicación histórica en la producción de eunucos, la cual se extendió por Asia durante la antigüedad y el medioevo. Se entiende por tales a los individuos que pierden sus testí- culos antes de la pubertad, con lo que se impide el desarrollo de los caracteres sexuales secundarios y de la libido dirigida hacia el sexo femenino. Esta circunstancia permitía el empleo de estos sujetos en oficios tales como masajistas y guardianes de harenes. El códice indio "Kama Sutra" regulaba la conducta sexual de estos individuos. Posteriormente, en los siglos XVII y XVIII, se practicaba la castración en los infantes del coro de las iglesias, para impedir el cambio de voz; de esa manera se lograban los varones sopranos, necesarios toda vez que la religión católica prohibía la presencia de mujeres en sus coros. Es célebre el caso del cantante napolitano Carlo Broschi, conocido por Farinelli (17051782), cuya vida fue llevada al cine en 1994 por el director belga Gérard Corbiau.

La castración es la única medida segura para prevenir el adenocarcinoma prostático, y una de las modalidades terapéuticas más eficaces en los estadios avanzados de la enfermedad.

Tema biomédico: Cuadro clínico del adenocarcinoma renal.

Tema cultural: La nota equivocada.

El Dr. Enrique Cabrera Cossío fue un destacado cardiólogo mexicano que prestó sus servicios durante varios años en Cuba, en el Hospital Nacional, que hoy lleva su nombre. El Dr. Cabrera era además un exquisito pianista. En cierta ocasión ejecutaba al piano una de sus melodías preferidas; solía hacerlo de memoria, sin ayuda de partitura, y esa vez hubo de equivocar una nota. Esto le llenó de gran preocupación, que manifestó a un colega neurólogo, quien decidió realizarle algunos estudios. Los resultados fueron preocupantes: el Dr. Cabrera padecía de un tumor cerebral. Una riesgosa operación logró la extirpación del tumor sin lesionar estructuras vitales. Se preveía una buena recuperación y todo era optimismo hasta que llegó el resultado de la biopsia: metástasis de un tumor de células claras.

La metástasis al sistema nervioso central es una de las múltiples formas de presentación del "Gran Simulador" de la Urología: el adenocarcinoma renal o hipernefroma.

Tema biomédico: Priapismo.

Tema cultural: Un dios hipererótico ${ }^{6,15,16}$.

El término priapismo se deriva de la mitología griega y proviene directamente del nombre del dios griego Príapo, conocido como hijo de Afrodita (la diosa del amor sexual, la belleza y la fertilidad 
femenina y, en algunas descripciones, también de la seducción y la violación) y de Dionisos (dios de la fertilidad, la vegetación y el vino). Príapo era invocado no solo para aumentar la fertilidad sino también la producción agrícola, la caza y, generalmente, los buenos resultados de cualquier empresa. Sus estatuas lo representaban con la túnica levantada por el pene en erección. Sus adoradoras buscaban unirse con él mediante salvajes danzas nocturnas. Los romanos, sin embargo, colocaban crudas imágenes de Príapo en sus jardines, que servían como espantapájaros.

El priapismo es el hilo conductor de la novela "Príapos", del escritor uruguayo Daniel Chavarría.

Tema biomédico: Enfermedad de Peyronie.

Tema cultural: El médico del Rey Sol ${ }^{6,17,18}$.

Luis XIV de Francia, el "Rey Sol" fue un importante promotor cultural. Mandó construir esa joya arquitectónica, el Palacio de Versalles, que hizo adornar con los cuadros de los más célebres pintores franceses de su época, y que fue sede de numerosos conciertos y bailes. Auspició la representación de las obras de Molière y creó la Comédie Française. Fundó también las Academias de Pintura y Escultura, de Ciencias y de Arquitectura. A la duración de su reinado (1643-1715, el más largo de toda la historia europea), contribuyeron las atenciones que recibió de su último médico, François de la Peyronie, el mismo que años después habría de describir la induración plástica del pene, enfermedad que lleva su nombre.

Tema biomédico: Impotencia sexual (disfunción eréctil).

Tema cultural: El peor de los fantasmas ${ }^{13}$.

En su novela "El amor en los tiempos del cólera", Gabriel García Márquez nos describe magistralmente un episodio de disfunción sexual: “...ella extendió la mano en la oscuridad, le acarició el vientre, los flancos, el pubis (...) Luego dio el paso final: lo buscó donde no estaba, lo volvió a buscar sin ilusiones, y lo encontró inerme. -Está muerto- dijo él. Le ocurrió siempre la primera vez, con todas, desde siempre, de modo que había aprendido a convivir con aquel fantasma: cada vez había tenido que aprender otra vez, como si fuera la primera."

\section{REFERENCIAS}

1. McManus IC. Humanity and the medical humanities. Lancet 1995;346(8983): 1143-1145.

2. Squier HA. Teaching humanities in the undergraduate medical curriculum. En Greenhalgh T, Hurwitz B. (Eds). Narrative based medicine. Londres: BMJ books, 1998:128-139.

3. Hawkins AH, McEntyre MC. (Eds). Teaching literature and medicine. Nueva York: The Modern Language Association, 2000:1-28.

4. Baños JE. El valor de la literatura en la formación de los estudiantes de medicina. Educ med 2003:6(2):37.

5. Ministerio de Educación. Pedagogía. La Habana: Pueblo y Educación, 1984:188-196.

6. Enciclopedia Encarta. Barcelona, 1998.

7. Santa Biblia (Versión Reina Valera). San José (Costa Rica): Caribe, 1980: 2024

8. Betto F. Entre todos los hombres. La Habana: Caminos, 1998: 34-35.

9. Morriña O. Acercamiento elemental a la forma. La Habana: Pueblo y Educación, 1974:62.

10. García Márquez G. Crónica de una muerte anunciada. La Habana: Casa de las Américas, s/f:80-82.

11. Balcells Gorina A. Patología general. La Habana: Edición Revolucionaria, 1972: 5.

12. Dictionnaire Encyclopédique Nouveau Petit Larousse. La Habana: Pueblo y Educación, 1970:1374.

13. García Márquez G. El amor en los tiempos del cólera. La Habana: Arte y Literatura, 1986:48-9,449.

14. Amaro Méndez S. Breve historia de la endocrinología. La Habana: Científico-Técnica, 1975:187-8.

15. Glenn JF. Cirugía urológica. La Habana: Científico-Técnica, 1987:809.

16. Chavarría D. Príapos. La Habana: Letras Cubanas, 2005.

17. Peyronie F de la. Sur quelques obstacles qui s'opposent á l'éjaculation naturelle de la semence. Mém de l'Acad Roy de Chir (París) 1743:425.

18. Critchley M. (Ed). Butterworths medical dictionary. 2 ed. La Habana, Edición Revolucionaria, 1987:1288.

Correspondencia: Dr. Á.M. Tundidor Bermúdez

Servicio de Urología.

Hospital General Docente "Guillermo Domínguez"

Puerto Padre, Las Tunas. Cuba

E-mail autor: tundidor@villazul.ltu.sld.cu

Información artículo: Original - Historia de la Urología

Trabajo recibido: mayo 2008

Trabajo aceptado: junio 2008

\section{COMENTARIO EDITORIAL}

La sugerencia que se nos ofrece, al margen de los condicionamientos de cada país, tiene cabida en todas las disciplinas universitarias y en todas las áreas de conocimiento científico y tecnológico, en las que las manifestaciones humanísticas deberían conservar un papel muy importante. En nuestro entorno corresponde a los profesores de Historia de la Medicina el incluir estas aportaciones en el tema explicado, aunque no es frecuente introducir narraciones literarias o pasajes de libros de los que encontramos excelentes modelos, equiparables a los 
expuestos en el artículo, en nuestros clásicos, en el Quijote, en la Celestina, en las comedias de Lope de Vega, etc., al igual que explayarse en glosar actos médicos en el arte de la pintura.

Con el continuo avance de la Medicina, la docencia se halla inmersa en un cambio, junto con toda la Universidad europea, para adecuarse a los criterios del nuevo articulado del proceso de Bolonia, donde se añaden modificaciones sustanciales en la enseñanza ya que el estudiante pasa a ser el centro del aprendizaje y el profesor tiene que reunir todos sus esfuerzos para que sea el alumno quien adquiera por sí mismo y bajo su dirección los conocimientos; con ello, creemos, la relación profesor alumno será más cercana y directa lo que propiciará el que se establezca un vínculo más accesible para referir o comentar ejemplos como los que nos ocupan, fácilmente extrapolable al sistema de preparación de especialistas, como el MIR español, y de este modo ampliar también su adiestramiento cultural, aconsejable para el ulterior desarrollo de trabajos científicos.

Honra al autor su preocupación por incrementar la formación humanística del estudiante al incluir estos temas en las disciplinas biomédicas y es de agradecer la labor de recopilación que ha realizado, recordemos que en el Renacimiento el saber de los médicos era más valorado cuanto mayor número de citas podía recitar de memoria. Lo difícil, y ese es otro mérito suyo, es descubrir, recoger y guardar textos y pasajes para exponerlos en el momento preciso, con lo que se nos recuerda la importancia de la educación humanística que tradiacionalmente ha constituido una de las características en la que destacaban los ejercientes de la Ciencia Médica y con la que se les reconocía.

Fdo.: Dr. M. Pérez Albacete 